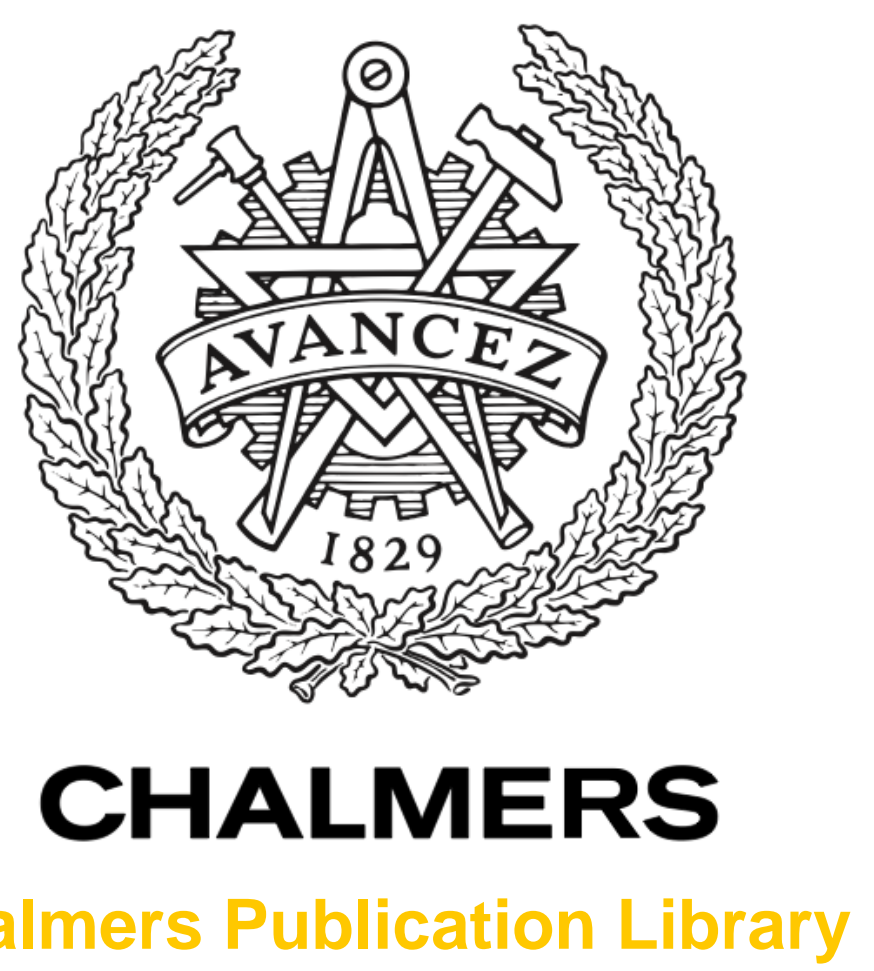

\title{
Punching/Shear Strength of a Full-scale Tested Bridge Deck Slab
}

This document has been downloaded from Chalmers Publication Library (CPL). It is the author's version of a work that was accepted for publication in:

39th IABSE Symposium - Engineering the Future, Vancouver, Canada

Citation for the published paper:

Shu, J. ; Plos, M. ; Zandi Hanjari, K. et al. (2017) "Punching/Shear Strength of a Full-scale Tested Bridge Deck Slab". 39th IABSE Symposium - Engineering the Future, Vancouver, Canada pp. 1750-1757.

Downloaded from: http://publications.lib.chalmers.se/publication/253570

Notice: Changes introduced as a result of publishing processes such as copy-editing and formatting may not be reflected in this document. For a definitive version of this work, please refer to the published source. Please note that access to the published version might require a subscription. 


\title{
Punching/Shear Strength of a Full-scale Tested Bridge Deck Slab
}

\author{
Jiangpeng Shu, Mario Plos, Filip Nilenius, Kamyab Zandi \\ Chalmers University of Technology, Gothenburg. Sweden
}

Niklas Bagge

Luleå University of Technology, 97187 Luleå, Sweden.

\section{Morgan Johansson}

Chalmers University of Technology, Gothenburg. Sweden

Norconsult AB, Theres Svenssons gata 11, 41755 Gothenburg, Sweden

Contact: shuj@chalmers.se

\section{Abstract}

For reinforced concrete (RC) slabs without shear reinforcement, shear and punching can be the governing failure mode at ultimate limit state if subjected to large concentrated loads. Punching of $\mathrm{RC}$ slabs without shear reinforcement has been a challenging problem in assessment based on current standards. To examine a previously developed enhanced analysis approach, this study was conducted by applying continuum FE analyses to a 55-year old RC bridge deck slab subjected to concentrated loads near the main girder in a field failure test. The influence of parameters such as boundary conditions, location of concentrated loads and shear force distribution were investigated.

Keywords: Shear and punching of RC slabs, Bridges, FE analysis, full-scale bridge test

\section{Introduction}

For reinforced concrete slabs without shear reinforcement, shear and punching can be the governing failure mode at ultimate limit state when subjected to large concentrated loads. Currently, building codes of practice provide several approaches to check the two-way punching strength of flat concrete slabs.

According to previous studies, non-linear FE analysis was able to predict shear and punching capacity with high accuracy, for example, Polak et al. [1] and Shu et al. [2]. Recommendations on how to make modelling choices when using 3D continuum elements was also presented in Shu et al. [3][2]. Results showed that not only the shear and punching capacity could be predicted, but also that influence of parameters such as specimen size and amount of flexural reinforcement was reflected in the non-linear FE analysis.
Furthermore, the shear force distribution in RC slabs and its relation to the critical shear crack has been investigated using continuum element FE analysis in Shu et al. [4]. However, all the studies mentioned above were carried out based on laboratory experiments. The application of these methods to structures in reality is also needed to show their applicability and advantage. In the past, only a limited number of the bridges deck slabs have been tested to failure. In addition, the developed enhanced analysis method has not been applied on such field tests.

The aim of this study was to examine the developed modelling methods developed by Shu el al.[2][3] and investigate the response of a real structure in engineering practice. A full-scale field test has been carried out to a 55 -year existing RC bridge [5], with a failure test of the deck slab under concentrated load near the girder, leading to a shear type failure of the slab; Figure 1. 
(a)
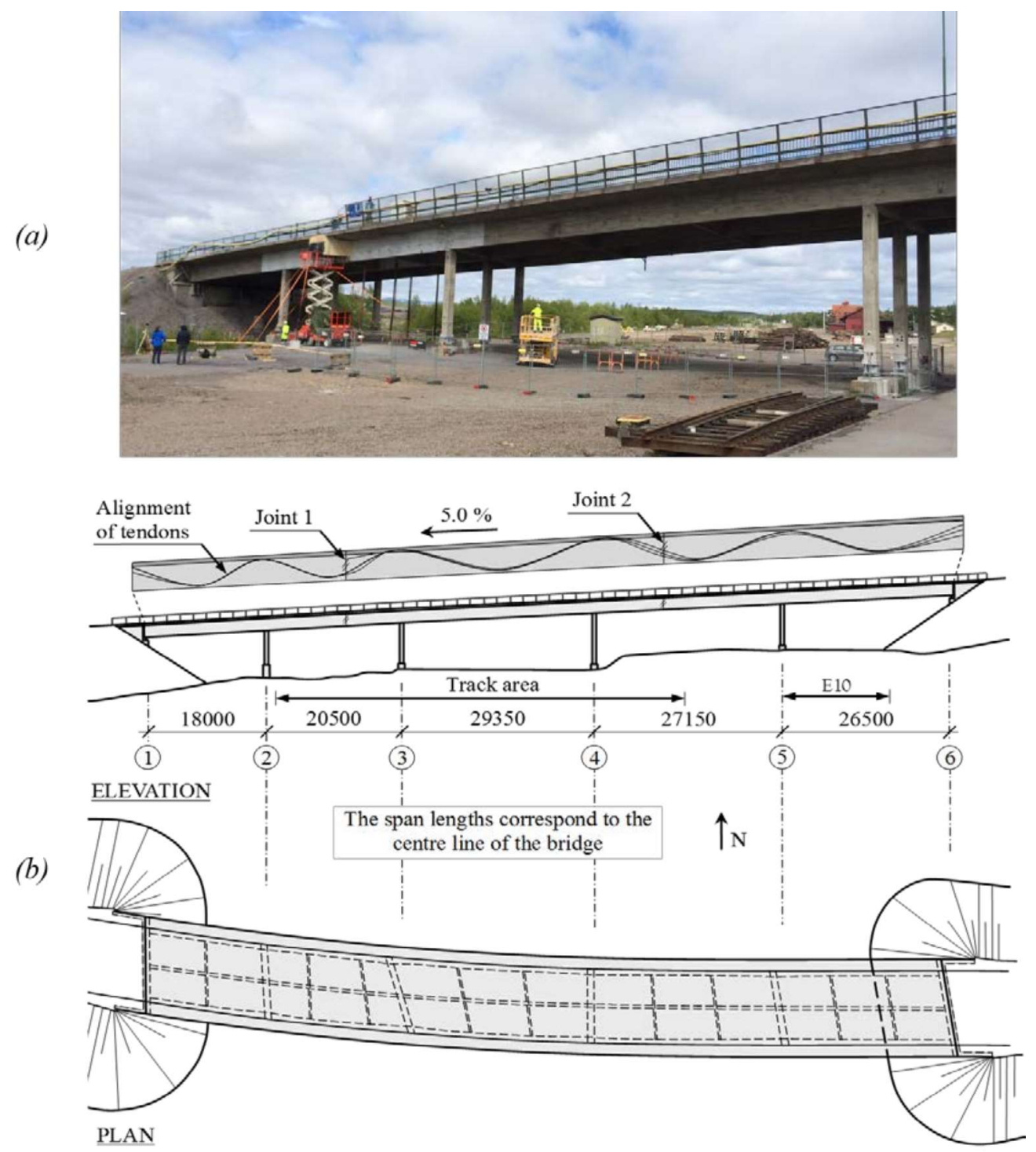

Figure 1: (a) Photo of the bridge and (b) geometry of the bridge.

\section{FE analyses}

\subsection{FE model}

In the FE model, the tested span including columns was modelled by a detailed 4-node brick element model and the remaining part of the bridge was modelled using 2-node beam elements as displayed in Figure $2(a)$. At least 8 elements were used in the thickness direction to sufficiently reflect the flexural behaviour [3]. For the part of the bridge modelled with beam elements. The part modelled with brick elements was connected to the part modelled with beam elements assuming that the connected cross-section, perpendicular to the beam main axis, remained plane and un-deformed, with the same rotations and deflections as the connected beam element. The reinforcement was included in the model as fully bonded embedded reinforcement bars, in accordance with the layout in the original drawings. 


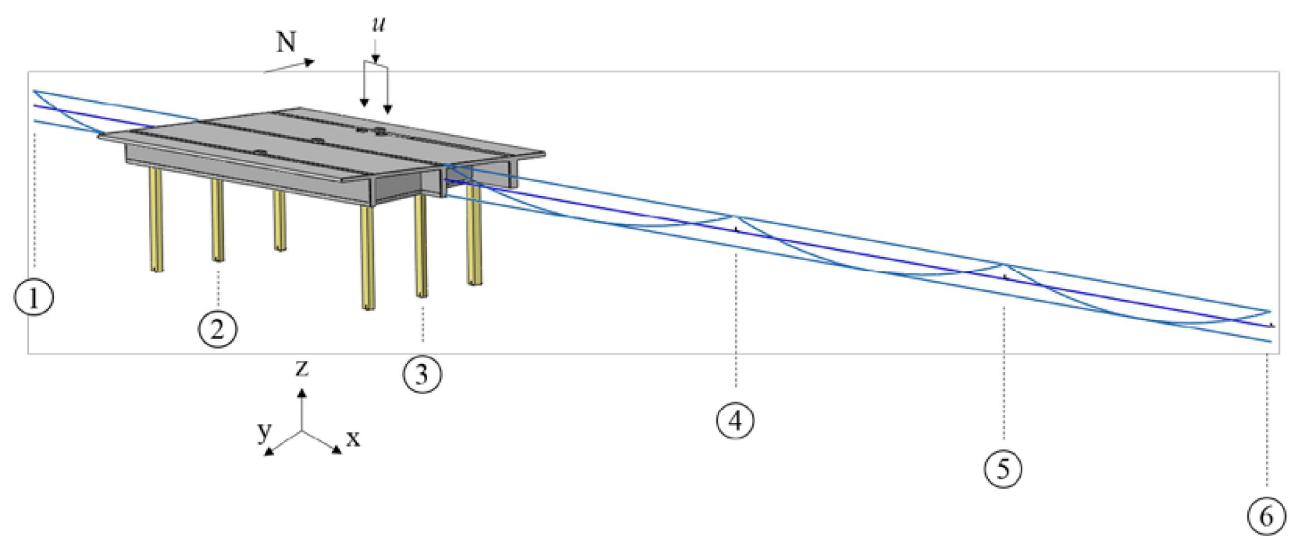

Figure 2. FE analyses: non-linear FE model of the tested bridge, showing supports 1-6.

The bridge was simply supported at the end abutments and at the bottom of the columns at support 2 and 3 . Supports 1-5 were constrained for displacement in vertical, transverse and longitudinal directions of the bridge but support 6 was allowed displacement in longitudinal direction. The bridge was preloaded with concentrated loads above the girders before the concentrated load was applied to the slab. The analysis was carried out using a Quasi-Newton iteration method based on force and energy convergence criteria, with a tolerance of 0.01 .

\subsection{Material models}

In all calculations, material parameters were obtained from the in-situ tests or from calculation see Table 1. For the material model, concrete was modelled using a fracture energy based total strain crack model; see Figure 3. The response of concrete in tension was described using a tension softening curve according to Hordijk [6] and the response in compression was described using a compression softening curve according to Thorenfeldt et al. [7]

Table 1. Input material parameters of concrete

\begin{tabular}{ccc}
\hline Items & Calculation method & Values \\
\hline Poisson's ratio & MC2010 & $v=0.15$ \\
\hline Tensile strength & MC2010 concerning reduction & $f_{c t m}=2.0 \mathrm{MPa}$ \\
\hline Fracture energy & MC2010 & $G_{f}=140 \mathrm{Nm} / \mathrm{m}^{2}$ \\
\hline Mean crack distance & $\mathrm{EC2}$ & $h_{b}=219 \mathrm{~mm}$ \\
\hline
\end{tabular}
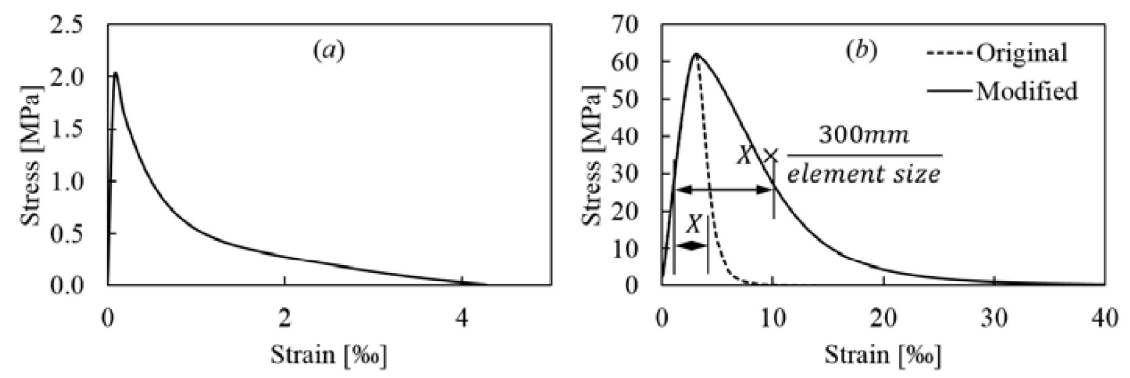

Figure 3. Material model of concrete: (a) response in tension; (b) response in compression. 


\section{Results and Parameter studies}

Load-carrying capacity and structural behaviour of the bridge deck slab has been obtained both from experiment and $\mathrm{FE}$ analyses. In addition, three parameters have been studied: Influence of structural model simplifications and boundary conditions; Influence of load positions and arching action; Shear force distribution.

\subsection{Load-carrying capacity and failure mode}

Load-deflection relationship from the continuum non-linear FE analysis are compared to

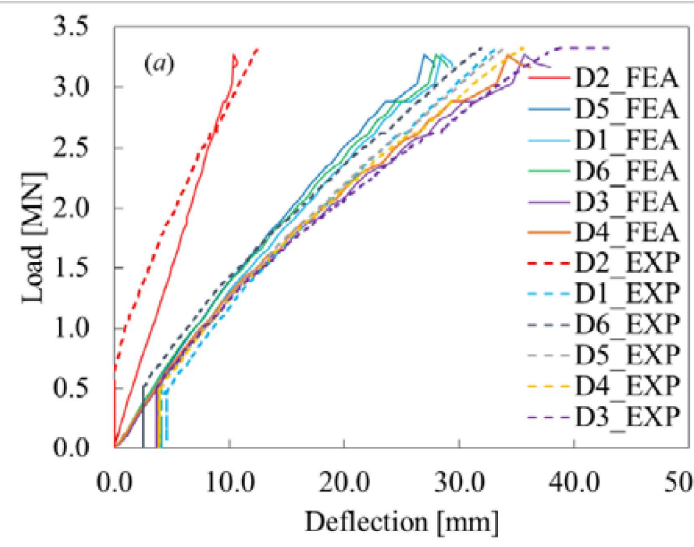

corresponding relationship from experiment in Figure 4. The deflections were taken from the model at the same position as in the experiment. Figure $4 \quad(a)$ shows the comparison of 6 measurement points on girders and slab and Figure $4 \quad(b)$ shows the comparison of measurement points under the two loading plates. A good agreement between continuum NLFEA and experiment was observed for both stiffness and final capacity.

Figure 4: Load-deflection relationship for FE analysis, compared to experiment results

The crack pattern at the bottom and top of the bridge deck slab after experiment is displayed in Figure $5(a)$ and $(b)$ respectively. This indicates that it was a combination of one-way shear and punching shear failure.

Figure $5(c)$ and $(d)$ illustrates the strain based crack pattern at the bottom of the slab and an isometric view with a cross section of the slab from the continuum FE analysis one loading increment before failure happened. In the FE analysis, at approximately $60 \%$ of failure load, a large shear

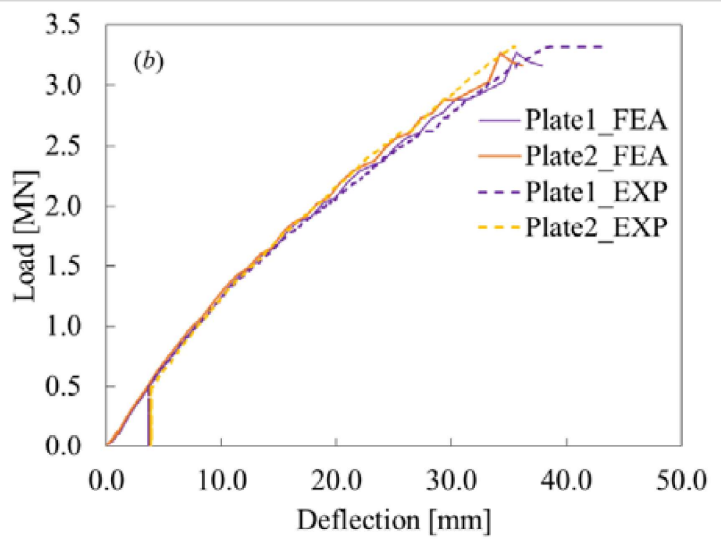

crack was developed between the loading plates and the girder. Just before the punching failure occurred, another shear crack developed on the other side of the loading plates and the failure occurred. At failure, the cracking in the FE analysis corresponded closer to a one-way shear failure than to a punching failure. In the experiment, shear failure occurred only adjacent to load 1 and no major shear crack was registered close to load 2. However, in the non-linear FE analysis, the failure crack propagated from load 1 to load 2, even though it was initiated adjacent to load 1. 


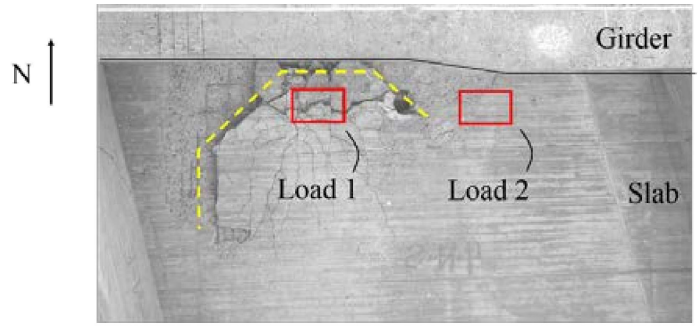

(a)

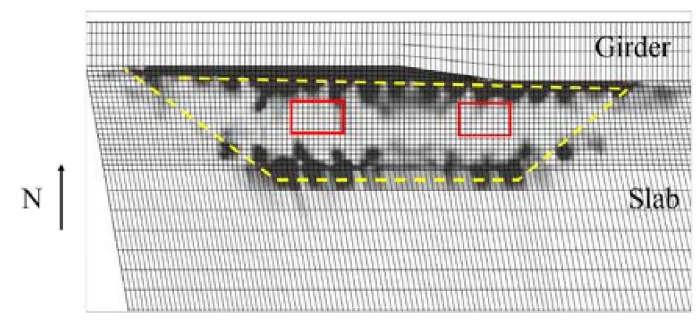

(c)

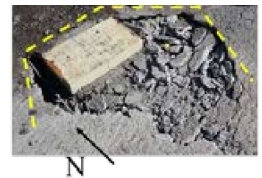

(b)

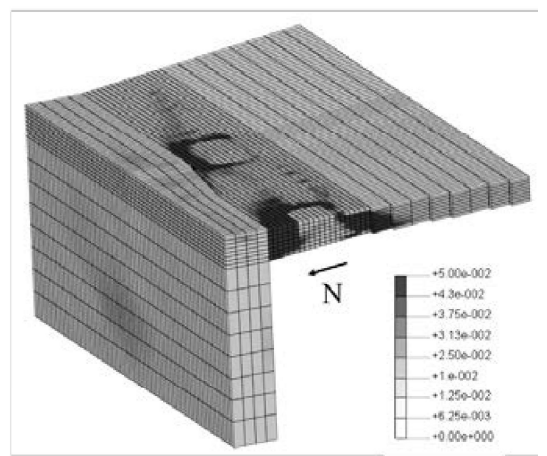

(d)

Figure 5: Photo of crack patter at final load level in experiment (a) at bottom of slab and at (b) top of slab in experiment; crack pattern from FEA: at (c) bottom of slab and at (d) isometric view of cross section

\subsection{Influence of boundary conditions}

The study was carried out by studying four different structural models with different boundary conditions (see also Figure 6): (i) Model including the loaded half span of the slab, clamped on the north side at the connection to the main girder and with symmetry boundary conditions on the other three edges (ii) Model including the loaded half span of the slab, simply supported on the north side and symmetry boundary conditions on the other three sides (iii) Model including the loaded half span of the slab, the girder closest to the load and the closest cross beams. (iv) Model including the tested $2^{\text {nd }}$ span of the bridge. $(v)$ Model including the entire bridge. The prestress of the main girders was included only in models (iv) and $(v)$.

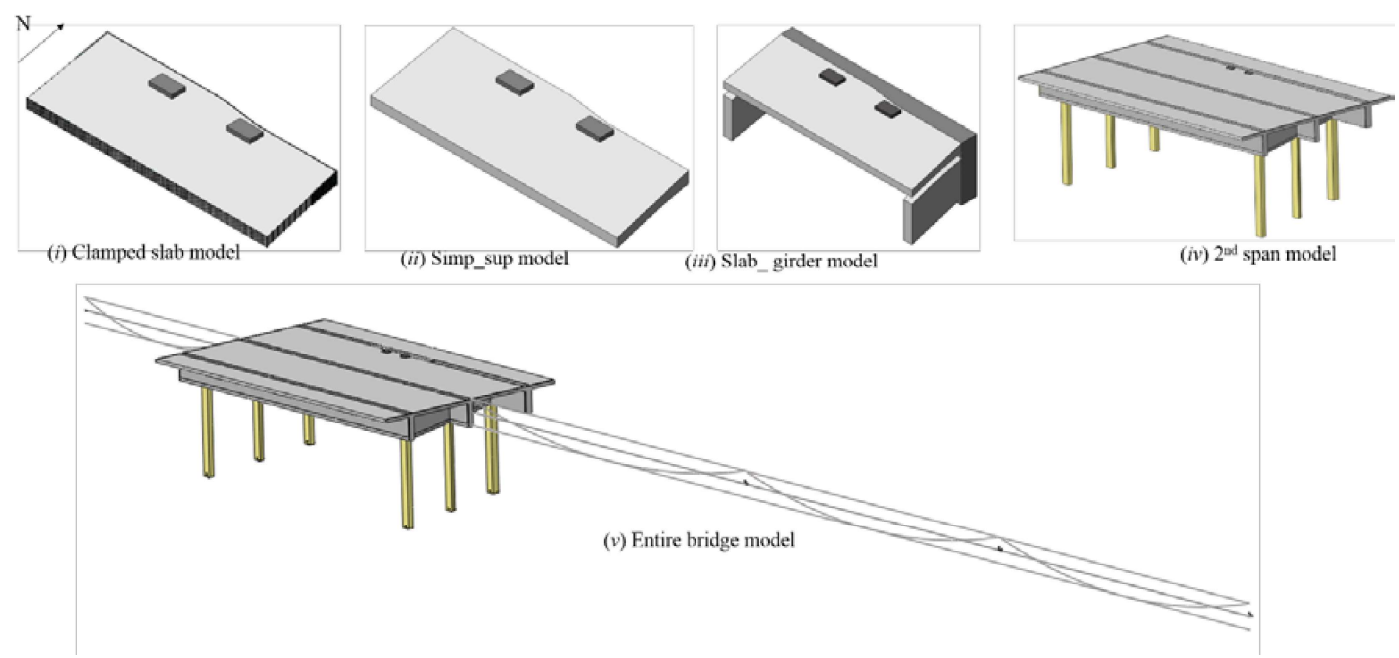

Figure 6. Assumed five boundary conditions in different models

Figure 7 illustrates load - deflection relationship for loading plate 1 for the different models. It was observed that model $(i)$, showed too stiff response but that the shear capacity was predicted with reasonable accuracy. Model (ii) showed too soft response and bending failure occurred instead of 
shear type failure for a low load. Model (iii) had a similar stiffness as in the experiment but the shear capacity was underestimated by $30 \%$. Model $(v)$ provide a rather accurate estimation of the response as well as the load carrying capacity. It was also observed that model (iv), only including the $2^{\text {nd }}$ span of the bridge, showed a structural behaviour rather close to that observed in the experiment and predicted by model ( $v)$, but the computation cost for models (iv) and ( $v$ ) was very similar.

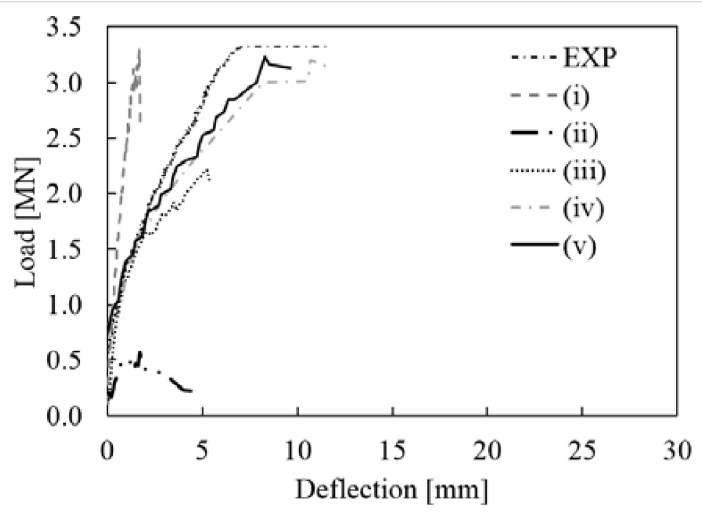

Figure 7. Load-deflection relationship of the loaded slab with different boundary conditions

\subsection{Load positions and arching action}

Assuming one-way shear failure occurred on the slab during the test, the arching action usually

(a)

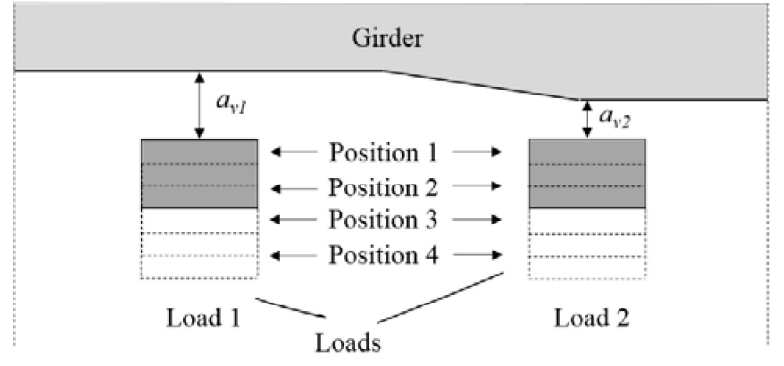

needs to be taken into account when loads are close to the support. According to EC2 [8], for members with loads applied on the upper side within a distance $0.5 d \leq a_{v} \leq 2 d$ from the edge of a support, the contribution of the load to the shear force $V_{E d}$ may be multiplied by a factor $B=a_{v} / 2 d$. According to MC2010 [9], arching action is also accounted for in a similar way. The contribution of point loads, applied within a distance $d \leq a_{v} \leq 2 d$ from the edge of the support, to the shear force may be reduced by the factor $B=a_{v} / 2 d \leq 1$.

In the bridge test, the distance from the edge of the loads to the edge of the girder were only $1.09 d$ and $0.6 d$ for load plate 1 and load plate 2, respectively. To study the influence of arching action, the loads were gradually moved further away $(100 \mathrm{~mm}$ per step) from the girder (see Figure $8(a)$ and Table 2. The nominal shear capacities were calculated assuming the a pure one-way shear failure and then values were compared to laboratory test results obtained by Natario et al. [10] and Lantsoght et al. [11]; see Figure $8(b)$. From the analysis results, it was observed that the shear capacity decreased when loads were moved further away from the support. When the loading plates were placed in position 4 , the failure mode even changed from shear to bending failure. (b)

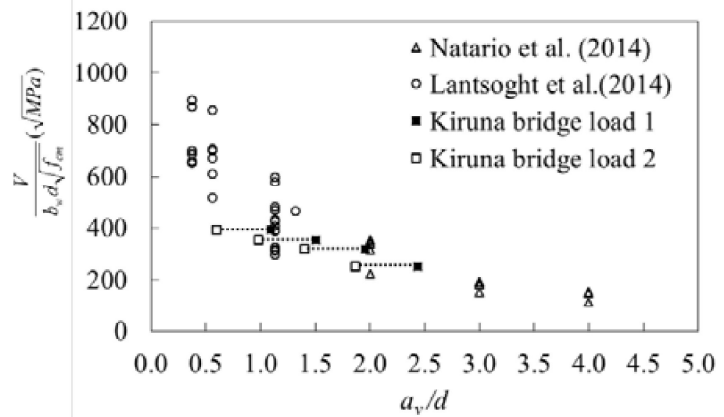

Figure 8: (a) Variation of load positions in the analysis of the tested bridge and (b) nominal shear capacity of the slab subjected to loads at different positons, with comparison to literature [10][11] 
Table 2: Variation of load positions, shear span ratios and load carrying capacity from the analysis of the tested bridge.

\begin{tabular}{cccccccc}
\hline \multirow{2}{*}{$\begin{array}{c}\text { Load } \\
\text { positions }\end{array}$} & \multicolumn{3}{c}{ loading plate $\mathbf{1}$} & \multicolumn{3}{c}{ loading plate 2 } & Capacity \\
\cline { 2 - 7 } & $\boldsymbol{d}_{\mathbf{1}}[\mathbf{m m}]$ & $\boldsymbol{a}_{\mathbf{v} 1}[\mathbf{m m}]$ & $\boldsymbol{d}_{\mathbf{1}} / \boldsymbol{a}_{\mathbf{v} \mathbf{1}}$ & $\boldsymbol{d}_{\mathbf{2}}[\mathbf{m m}]$ & $\boldsymbol{a}_{\mathbf{v} 2}[\mathbf{m m}]$ & $\boldsymbol{d}_{\mathbf{2}} / \boldsymbol{a}_{\mathbf{v 2}}$ & [MN] \\
\hline 1 & 270 & 295 & 1.09 & 259 & 155 & 0.60 & 3.28 \\
\hline 2 & 262 & 395 & 1.51 & $259 *$ & 255 & 0.98 & 2.72 \\
\hline 3 & 253 & 495 & 1.96 & 253 & 355 & 1.40 & 2.34 \\
\hline 4 & 244 & 595 & 2.44 & 244 & 455 & 1.86 & 2.00 \\
\hline
\end{tabular}

* The $d_{1}$ and $d_{2}$ are taken at the critical section using 45 degree dispersion. Load plate 2 is too close to the girder, so critical section is the same for position 1 and 2 .

\subsection{Shear force distribution}

In Figure 9, the shear force per unit length along a line in the longitudinal direction of the bridge close to the girder is presented for different load levels. A clear shear force redistribution was observed for the shear force near loading plate 1: the shear force close to loading plate increased fast as the applied load increased at low load levels $\left(Q / Q_{u} \leq\right.$ 0.8 ), but stopped to increase at higher load levels $\left(Q / Q_{u}>0.8\right)$. Instead, the shear force in the adjacent region increased faster. Similar observation was also presented for the reaction force along a slab support by Natario et al.[10].

According to French practice, the effective width for shear force distribution should be limited to the area within 45 degree angles from the edges of the loaded area. The shear force within this region (grey shadow) was observed to be much higher than the adjacent region.

Distance to center of loading $[\mathrm{mm}]$

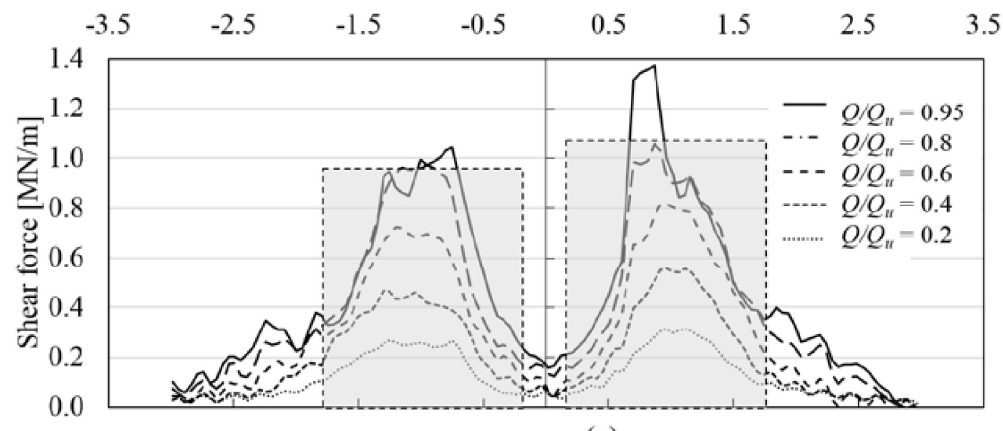

(a)

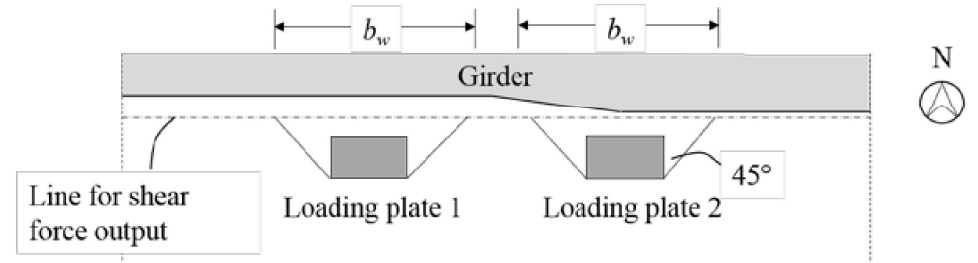

Figure 9: Unitary shear force across a line parallel to the girder, from FE analysis with continuum elements.

The shear force per unit length around the two loading plates, at a distance of $0.5 \mathrm{~d}$, was also studied for different load levels; see Figure 10. As expected, the magnitude of the shear force on the north side of loading plate 1 , towards the closest girder, is much higher than that on the south side, whereas, the magnitude of shear force on the east and west sides of the loading plates is in between. The difference in shear force between the difference sides of the loading plates also support the conclusion that the failure mode is a combination of one-way shear and punching shear, but one-way shear is more dominant. 


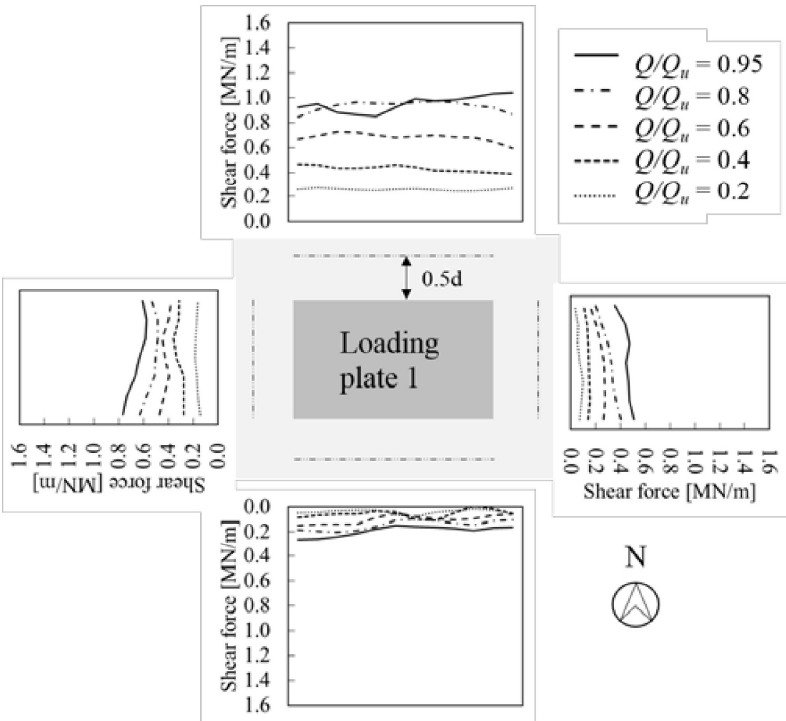

Figure 10: Shear force per unit length around the loading plates, from FE analysis with continuum (brick) elements.

\section{Conclusions}

The tested RC bridge deck slab failed in a combination of one-way shear and punching shear. This kind of shear type failure as well as structural response of the slab could be reflected using continuum non-linear FE analyses with a model including the entire bridge with reasonable simplifications.

a. The extent of the FE model, as well as the assumption of boundary conditions for the tested slab has significant influence on the analysis results.

b. The location of applied load plays an important role. When the load was moved further away from the closest girder in the continuum FE analysis, the load-carrying capacity with respect to shear was decreased until the failure mode changed from shear to bending.

c. In addition, the analysis of shear force distribution also shows that the method using a 45 degree dispersion to define effective width is reasonable.

\section{References}

[1] A. Polak, "Modeling Punching Shear of Reinforced Concrete Slabs Using Layered
Finite Elements," ACl Struct. J., vol. 95, no. 1, pp. 71-80, 1998.

[2] J. Shu, M. Plos, M. Johansson, K. Zandi, and F. Nilenius, "Prediction of punching behaviour of RC slabs using continuum non-linear FE analysis," Eng. Struct., 2016.

[3] J. Shu, D. Fall, M. Plos, K. Zandi, and K. Lundgren, "Development of modelling strategies for two-way RC slabs," Eng. Struct., vol. 101, pp. 439-449, 2015.

[4] J. Shu, M. Plos, B. Belletti, and A. Muttoni, "Internal force distribution in RC slabs subjected to punching shear: shell and solid non-linear FE analyses," Eng. Struct., no. Submitted, 2016.

[5] N. Bagge, "Assessment of Concrete Bridge: Models and Tests for Refined Capacity Estimation," Luleå University of Technology, Luleå, 2014.

[6] D. A. Hordijk, "Local approach to fatigue of concrete.pdf," Delft University of Technology, Delft, Netherlands, 1991.

[7] E. Thorenfeldt, A. Tomaszewicz, and J. J. Jensen, "Mechanical properties of highstrength concrete and applications in design," in In Proc. Symp. Utilization of High-Strength Concrete, 1987.

[8] CEN, Eurocode 2: Design of concrete structures - part 1-1: General rules and rules for buildings. Brussels, Belgium: CEN European Committee for Standardization, 2004.

[9] fib, Model Code for Concrete Structures 2010. Lausanne: International Federation for Structural Concrete (fib), 2013.

[10] F. Natário, M. Fernández Ruiz, and A. Muttoni, "Shear strength of RC slabs under concentrated loads near clamped linear supports," Eng. Struct., vol. 76, pp. 10-23, 2014.

[11] E. Lantsoght, C. Veen, and J. Walraven, "Shear in One-Way Slabs under Concentrated Load Close to Support," $\mathrm{ACl}$ Struct. J., no. 110, pp. 275-284, 2014. 